\title{
El primer director del Diccionario Enciclopédico Hispano- Americano de Montaner y Simón
}

PILAR PARDO HERRERO

Universitat Autònoma de Barcelona

La aproximación a una obra lexicográfica es natural que tenga como punto de partida el contenido de sus páginas. Ciertamente allí está una información fundamental pues se encuentra el texto definitivo, entendiendo por definitivo el texto impreso. Pero ese texto que llega a las manos del lector ha transitado un camino, ha escrito una historia, cuyo conocimiento y divulgación completan el significado de la obra como un todo.

A la historia a la que se refiere este artículo es a la del inicio del Diccionario Enciclopédico Hispano-Americano de literatura, ciencias y artes (DEHA en adelante) de Montaner y Simón, Editores, y el propósito es establecer quién fue su primer director, lo que redunda en una mejor comprensión del contenido de la obra.

Como intentaré establecer en estas páginas, el contenido del $D E H A$ encierra muchos significados, muchos más que sencillas definiciones de tal o cual voz, dónde está ubicado un pueblo o quién es un determinado personaje. De hecho, leer el DEHA en profundidad hace que se pueda considerar un importante documento histórico pues en él se pueden hallar muestras del pensamiento español correspondiente a la época en que se escribe, lo que se demuestra en trabajos sobre el DEHA como los de Gutiérrez Cuadrado (1994), Jiménez (1996), Chabrán (2000) y Pardo Herrero (2012). Pero además, la observación de la obra, interpretándola más allá de las palabras, acompañada de documentación histórica permite desentrañar parte de su proceso de elaboración, cuestión relevante a la hora de entender el contenido, así como escribir una historia más completa de la lexicografía del español.

Es en la historia editorial del $D E H A$ en lo que se concentra este texto, con el ánimo de establecer quién estuvo a cargo del proyecto en un inicio y la huella que ese autor deja en los primeros pliegos del primer tomo.

\section{BREVE INTRODUCCIÓN AL DEHA}

El DEHA fue publicado en Barcelona por Montaner y Simón, Editores y consta de tres partes. La primera y principal la constituye el cuerpo del diccionario, que tiene 23 tomos (en 24 volúmenes) impresos entre 1887 y 1898 . La segunda la forma el primer

${ }^{*}$ El estudio se enmarca en el proyecto dirigido por el Dr. Cecilio Garriga Escribano Diccionario histórico del español moderno de la ciencia y de la técnica financiado por la Secretaría de Estado de Investigación, desarrollo e innovación del Ministerio de Economía y Competitividad (FFI2013-41711-P), proyecto desarrollado por el grupo Neolcyt, grupo consolidado de la Generalitat de Catalunya (2009SGR937) y que forma parte de la Red Temática «Lengua y ciencia» (FFI2009-05433-E). 
apéndice, con dos volúmenes impresos en 1898 y 1899 que siguen la numeración a partir del cuerpo, es decir que se consideran el tomo $24 .^{\circ}$ y $25 .^{\circ}$ La tercera y última, ya en el siglo XX, es el segundo apéndice, con tres volúmenes, del 26 al 28, impresos entre 1907 y $1910^{1}$. Entre el cuerpo y los apéndices la obra tiene 31.272 páginas en las que se hallan alrededor de 250.000 entradas.

Pese a haber sido una obra de gran envergadura con un buen número de ejemplares publicados (el primer volumen podría haber superado los 18.000) (Pardo Herrero 2012: 62), una recepción amplia y verificable en España y América (2012: 79-99) y un contenido léxico y enciclopédico de interés, su estudio en profundidad no se consideró relevante hasta poco más de un siglo después del inicio de la publicación, cuando Gutiérrez Cuadrado (1994) llamó la atención sobre él. A este artículo siguieron algunos otros textos parciales entre los que destacan los de Prieto García-Seco (2007, 2008, 2009, 2010), tras los cuales continuó una investigación profunda realizada en mi tesis doctoral, centrada en esta obra con el objetivo de ponerla en el mapa de la lexicografía, así como en el de la divulgación científica y técnica, a la vez que dando luz sobre la historia editorial de la que fue fruto.

Sobre el contenido del DEHA hay mucho que decir, por lo cual me limito simplemente a indicar que su propuesta, enmarcada en la tendencia decimonónica de la lexicografía española hacia el enciclopedismo (Azorín 1996), hace que pueda verse como varias obras en una. Por un lado se presenta como un diccionario de lengua común -incluye la nomenclatura del DRAE 1884 (lo que se sabe comparándolos, pues no lo indica), otras voces comunes y antiguas que no tenía el diccionario académico y americanismos; a lo que se suma la recuperación del uso de ejemplos_-; por otro, la inclusión de voces de ciencia y técnica novedosas o no incluidas por el $D R A E$ indica que pretende ser también un diccionario técnico-científico (de las entradas de $D E H A$, aquellas con marca de especialidad en el cuerpo son alrededor de un $22 \%$, en el primer apéndice un $54 \%$ y en el segundo un 38\%); y por último, es una enciclopedia, por incluir nombres propios, y tratar muchas voces como conceptos de un determinado ámbito, además de dar extensas explicaciones en artículos generalmente separados de la definición concreta.

El proyecto que el contenido de la obra revela es clave en su vertiente lingüística, pero también como punto de partida para reconstruir cómo se llevó a cabo, pues dado que no hay ningún texto introductorio o prólogo que permita conocer los lineamientos con que se elaboró el diccionario, ni indicación de quién lo dirigió, son sus propias páginas a las que hay que acudir para discernir esa cuestión. A esa información debe sumarse igualmente la documentación histórica hasta hoy conservada y asequible, ya que ofrece datos invaluables en forma de cartas privadas, recibos de pago, libros de contabilidad, etc.

Considerar que saber quién dirigió el proyecto ayuda a entenderlo mejor, llevó a la necesidad de establecer esta cuestión. Por una parte, Gutiérrez Cuadrado (1994) y Ahumada (2007) daban como redactor-jefe y director, respectivamente, a Pelayo Vizuete, información real solamente para el segundo apéndice, efectivamente dirigido por él. Más cerca estaban Alonso et al. (2001) y Prieto García-Seco (2007 y 2009), quienes consideraban

\footnotetext{
${ }^{1}$ Una descripción detallada de la obra puede encontrarse en Pardo Herrero (2012: capítulo II).
} 
como director a Aniceto de Pagés. Pude comprobar esta hipótesis gracias a algunos documentos de la editorial en la Biblioteca de Catalunya, que han permitido acreditar, sumados a testimonios en fuentes como revistas de la época, que la persona que estuvo a cargo del $D E H A$ fue Aniceto de Pagès (Pardo Herrero y Garriga 2010: 456-457, Pardo Herrero 2012: 35-67), que en los listados de redactores aparece como encargado de Autoridades de la lengua española y luego también de la sección de Lexicografía. Según dicha documentación, Pagès estuvo a cargo del diccionario en todos los volúmenes del cuerpo ( 1 a 23, publicados entre 1887 a 1898), así como en los dos volúmenes que conforman el primer apéndice (24 y 25, publicados entre 1898 y 1899$)^{2}$.

\section{EL PRIMER DIRECTOR DEL DEHA}

Conocido el nombre de la persona que estuvo a cargo del proyecto casi de principio a fin, ¿por qué entonces considerar que antes de Pagès alguien más estuvo al frente del $D E H A$ ?

La respuesta se encuentra en las cartas preliminares de la gran obra lexicográfica de Pagès, su Gran diccionario de la lengua castellana, cuyo primer volumen se publica en 1902, el mismo año de su muerte. Allí, en la última carta, una persona cuyo nombre no aparece entre los redactores del $D E H A$, felicita al autor por la publicación y dice «yo vi á V. trabajar á mi lado precisamente en la selección de autoridades durante los cuatro meses que dirigí el Diccionario Enciclopédico de Montaner y Simón» (Pagès, 1902: $\mathrm{X})$. Esa persona es Eduardo Benot y Rodríguez.

Este testimonio comprueba por sí mismo que Benot dirigió temporalmente el proyecto, aunque la fecha no se especifica. Pero antes de esta declaración pública hay otros documentos privados que señalan el vínculo de Benot con el $D E H A$.

Como es lógico asumir, el proyecto enciclopédico lo tienen los editores tiempo antes de que el primer cuaderno salga de la imprenta. Por la correspondencia que hoy se conserva de algunos colaboradores de la editorial Montaner y Simón en la Biblioteca de Catalunya (Fons Montaner i Simon), el proyecto del DEHA estaba en la mente de los editores al menos desde 1883, y en el proyecto para ese momento estaba involucrado Benot. El 25 de febrero de ese año Francisco Pi y Margall, que colaboraba con la editorial y le servía también de abogado, dice a los editores:

Por Benot he sabido que [...] también tienen V.V. el propósito de publicar una enciclopedia. No saben V.V. cuántas veces he reñido [¿?] á Benot por no haber aceptado la proposición de V.V. demostrándole cuán fácil era hacer lo que él llama el esqueleto y yo llamo la armazón del diccionario. Aquí no tenemos ni una mediana enciclopedia pues la de Mellado sobre ser antigua está mal traducida y peor confeccionada y el Diccionario Universal de la lengua Castellana cuya propiedad disputamos es malo hasta decirlo de sobra. (25/02/1883)

Esta carta, aparte de mostrar opiniones del remitente sobre otras obras contemporáneas, demuestra que desde el inicio de 1883 los editores Montaner y Simón querían hacer una enciclopedia y que propusieron a Benot que les colaborara.

\footnotetext{
${ }^{2}$ Una transcripción del contrato firmado entre Pagès y los editores, así como de las cuentas de abono de los apéndices, que comprueban estas afirmaciones, se ofrecen al final de este artículo. La reproducción del contrato puede verse en Pardo Herrero (2012: 531).
} 
Aunque en la carta citada parece que Benot no aceptaría, en otra carta un poco posterior del mismo Francisco Pi y Margall, del 30 de abril de 1883, este dice: «Al fin Benot se ha encargado de hacer para V.V. un diccionario de la lengua. Lo hará bien porque tiene gran caudal de voces y de frases que no estará en ningún otro diccionario». Eduardo Benot sería, pues, en ese momento quien iniciaría y estaría a cargo del proyecto.

La falta de documentación privada de la editorial con sus colaboradores deja un vacío entre esta última carta citada y la próxima en la que hay comentarios sobre el $D E H A$ y sobre Benot. Cuando aparecen estos temas nuevamente es casi tres años después, en febrero de 1886, esta vez por la correspondencia enviada por Aniceto de Pagès a los editores. En una carta de Pagès a Francisco Simón del 10-11 de febrero de 1886 se hace evidente que Benot dirige el proyecto, pero tiene desavenencias con quien escribe, Pagès, a quien le parece que el trabajo de Benot no conduce al objetivo de publicar el diccionario por ser muy perfeccionista y estar más preocupado por la producción de contenidos que por la producción editorial global.

Al día siguiente, 12 de febrero de 1886, Pagès continúa en otra carta en la que comienza diciendo que «Benot es irremplazable», pero:

Odia los negocios, en especial el de libros, pues dice que con ellos no se debe comerciar. Es poco práctico en administrar y organizar, y su principal defecto consiste en decir á las personas que trabajan á sus órdenes que ganan poco y que debieran ganar más y que son unos infelices á quienes se explota á mansalva.

Por su parte, Pagès se precia de ser hombre práctico mas no hacedor de milagros, y de nuevo se lanza a la carga: "yo me encargo del Diccionario en la forma que U. [Sr. Simón] quiera y al precio que á U. le convenga y me comprometo [¿?] a sacarlo mejor que nadie en las mismas condiciones. Pero necesito poder moverme libremente». Estamos en el punto álgido de la tormenta, lamentablemente contando solo con un punto de vista. No sabemos qué decía Benot ni los editores.

Poco después, en la carta del día 6 de marzo de 1886, ya Pagès utiliza un tono en que se siente que está casi seguro de que saldrá victorioso de la contienda y estará a cargo del $D E H A$ : «estoy muy ocupado en tomar el pulso á muchas personas, con las cuales he de saber si puedo contar, caso de que me arregle con ustedes. Yo le aseguro que esta vez el diccionario se hace con relativa rapidez, ó no vuelvo ya á acordarme de semejante asunto.» $\mathrm{Y}$ así fue, consiguió tomar las riendas, y el 30 de marzo esto parece confirmarse con el envío de Benot a Pagès de una serie de obras que este tenía para organizar la enciclopedia, lista que se conserva en el fondo referido de la Biblioteca de Catalunya ${ }^{3}$.

\footnotetext{
${ }^{3}$ Las razones aquí expuestas para que el proyecto de obra de Benot no prosperara coinciden sin duda con las cuatro causas que para Gutiérrez Cuadrado (2012: 33) suelen ser los motivos que ocasionan el fracaso de un proyecto lexicográfico: 1. La personalidad del lexicógrafo, 2. los colaboradores, 3. el proyecto y 4. la economía. Al mismo Benot, triste sino, también se le quedó incompleto un proyecto posterior, el Diccionario de Ideas afines y elementos de Tecnología, del cual solo fue publicada la parte del diccionario (Gutiérrez Cuadrado 2012: 36).
} 
Según esta correspondencia, los meses de dirección a los que Benot se refería en la carta que aparece en el diccionario de Pagès, habrían de considerarse los últimos del año 1885 y los primeros de 1886 .

\subsection{Quién es Eduardo Benot}

Que los editores pensaran en Eduardo Benot como el hombre adecuado para la tarea de preparar una enciclopedia parece algo lógico si se tiene en cuenta el perfil que revela su biografía, conocida por los artículos dedicados en su tiempo por el propio DEHA (tomo 3, con una ampliación en el 24) y la Enciclopedia Espasa. Nacido en Cádiz en 1822 , escribe desde muy joven poesías y dramas, a las que pronto une artículos políticos a la vez que dedica tiempo a los estudios científicos y filológicos. Su preocupación por la ciencia se evidencia en su paso por el colegio de San Felipe Neri, donde comienza dando clase de lógica y acaba adquiriendo un tiempo después para hacer de él un centro reconocido y dotarlo de un gabinete de física y química de un nivel más que aceptable, preocupación que continúa toda su vida, como demuestra el hecho de que siguiera escribiendo sobre muchos temas de ciencia y que organizara el Instituto Geográfico y Estadístico. En su vertiente pública y política actuó como escritor y director de publicaciones periódicas como La Discusión, pero también fue miembro activo como vocal de las Juntas revolucionarias de 1869, como diputado de las Cortes constituyentes del mismo año, como ministro de Fomento durante la República y como diputado por Madrid en 1893 (tras unos años fuera del país). En 1887 ingresó en la Real Academia Española. Murió en Madrid el 27 de julio de 1907.

Entre sus obras se encuentran: Gramáticas francesa, italiana, inglesa y alemana (1851-1854), Aritmética general (c. 1895), Sistema métrico (c. 1895), Resultante de los movimientos giratorios con aplicaciones a la Astronomía (s.f.), En el umbral de la ciencia (1889), Arquitectura de las lenguas (c. 1900), Prosodia castellana y versificación (1901), Estudio acerca de Cervantes y el Quijote (1905), por mencionar solamente algunas ${ }^{4}$.

Como indican los datos sobre su trabajo profesional y sus obras, Benot era un hombre que tenía conocimientos de muchos campos. Señal de una inagotable curiosidad, su reflexión acerca de distintos temas permite considerarlo, hasta cierto punto, un enciclopedista tardío. Para elaborar una enciclopedia, elegir a Benot parece, pues, un acierto, si además se atiende a que uno de los ámbitos en que destacaba su saber era el de la gramática del español así como el estudio de otras lenguas. En la práctica, en la decisión de la casa editorial debió pesar el hecho de que ya lo conocían, pues escribía artículos sobre diversos temas para su revista La Ilustración Artística, ${ }^{5}$ en la que participaron varios de los redactores que luego vemos en el $D E H A$, incluido Pagès, aunque este con un cargo más «invisible»: buscar textos originales (sobre este aspecto en rela-

${ }^{4}$ Los datos correspondientes a las obras han sido obtenidos a partir de la biografía de Benot aparecida en el $D E H A$, la aparecida en la Enciclopedia Espasa y las recogidas por Palau y Dulcet.

${ }^{5}$ Algunos títulos, sacados de los recibos de pago por ellos que se conservan en el Fons Montaner i Simon de la Biblioteca de Catalunya, que muestran esa diversidad son: «Los átomos», «La unidad de la materia», «Terremotos», «Los volcanes», «Efectos fisiológicos de la presión del aire», «Etimologías», «Lingüística», «La historia en el lenguaje», «¿Es la tierra un perfecto cronómetro?», «El hélio». 
ción con el $D E H A$, véase Pardo Herrero 2012: 41-42). La elección a nivel ideológico resulta asimismo interesante, pues Benot era un conocido federalista y liberal, lo que a buen seguro tendría repercusión en los contenidos y planteamiento de la obra.

\subsection{Las huellas de Benot en el DEHA}

Una vez comentados algunos aspectos sobre la biografía de Eduardo Benot, y habiendo reconstruido la parte de la historia correspondiente al $D E H A$, es preciso dar un paso más y observar si en el $D E H A$ que se publicó hay rastros del trabajo que este habría comenzado a realizar.

Un primer indicio de que Benot participó en el $D E H A$ como productor de contenido se encuentra en la reseña del diario La Dinastía del 9 de marzo de 1887, aparecida cuando apenas comenzaba a publicarse la obra. Allí se alaba el diccionario y se mencionan escritores que «han colaborado y colaboran» (p.6); entre ellos, y pese a no estar en la lista que acompaña los volúmenes, está Benot, lo que lleva a considerar que efectivamente hubo colaboración de su parte al menos en el inicio.

Si retomamos la correspondencia que se conserva de Pagès y los editores, hay algunos comentarios que indicarían esa participación. En la carta del 10-11 de febrero de 1886 dice: «Don Eduardo tiene la manía de la perfección, y esto hace que nunca encuentre nada acabado. Se pasa días en estudiar si las abejas tienen el aguijón así o asá, y empleó una semana entera en averiguar si Aaron murió de 103 ó de 104 años. Y a mi parecer estos trabajos que honrarían á las primeras revistas del mundo no son propios para una enciclopedia». Esta carta señala que Benot estaba escribiendo artículos en ese momento, hablando de dos en particular, el de Aaron y el de abeja. El artículo enciclopédico de esta última entrada supera las siete páginas de texto, apoyadas en diversas ilustraciones; como dice Pagès, es todo un tratado, y podríamos pensar que fue escrito por Benot.

Lo que hubiera avanzado Benot se habría utilizado, al menos parcialmente, en el inicio del DEHA, lo que se corrobora con otras dos cartas de Pagès cuando está intentando organizar la publicación. Una es la carta del 27 de abril de 1886 al decir Pagès que hay que deshacer la estereotipia de lo hecho por Benot por estar los artículos incompletos («un solo hombre no puede entender de todo; es imposible») o que son heréticos. La otra es del 20 de noviembre de 1886, donde dice Pagès a Simón: «no deje de hacer todas las observaciones respecto a la Enciclopedia que juzgue necesarias, pues yo estoy casi tan interesado como ustedes en que la obra tenga buen éxito. Si así se hubiese hecho desde un principio no tendríamos ahora el maremagnum de corregir todo lo que hizo Benot». Esto deja claro que redactó e intervino en la confección, y que lo que pudo escribir se usó, no se desechó.

Todo lo dicho anteriormente tiene su comprobación efectiva en el DEHA. Al aproximarse a las páginas del primer tomo del diccionario se puede observar que hay cambios entre los primeros pliegos y el resto del tomo y del diccionario (para una descripción detallada de la macroestructura y la microestructura del $D E H A$ véase Pardo Herrero 2012: cap. II). Limitando el análisis a la lengua común allí contenida — las entradas sin marca de especialidad-, lo que sobresale es que los primeros catorce pliegos, que abarcan de la 
entrada $a$ a abellacado, un $10 \%$ de primer volumen, difieren del resto por tres cuestiones clave, fruto posiblemente de cómo Benot habría planteado la obra en un principio:

a. La notación gramatical,

b. la definición, $\mathrm{y}$

c. la etimología.

\subsubsection{La notación gramatical}

En los primeros catorce pliegos, con alguna excepción en ellos y alguna otra anecdótica más adelante en ese tomo primero o en los posteriores, la forma de indicar la categoría gramatical de la voz es compuesta (siendo posteriormente simple, como la de la Academia). Así, la referencia al inicio a un sustantivo masculino es: «s.m.», luego será «m.»; el sustantivo femenino es «s.f.», luego será «f.», el verbo transitivo, entonces llamado activo, es «v.a.», luego será solo «a.», entre otras marcas gramaticales. Además se utiliza la marca «met.» 'metafórico', mientras en el resto de la obra se usará, como en el DRAE, «fig.» 'figurado' (Pardo Herrero 2012: 169-174). Ejemplo de ello son, en los primeros pliegos:

ABARATAMIENTO: $s$. m. Acción y efecto de abaratar.

ABDUCCIÓN (del lat. abducť̌o, separación; de ad y ducěre, llevar); s. f. Acción de sacar hacia fuera y su efecto.

ABATIR (de $a$ y batir): v. a. Derribar, echar por tierra, desbaratar, deshacer, hacer bajar, bajar.

ABEJARUCO: $s$. m. Ave de medio pie de largo, hermosa por el color azul y verde de sus alas y el amarillo de su pecho. Persigue á las abejas. \| met. La persona ridícula cuyo trato causa enfado.

Posteriormente:

DICTADO (del lat. dictātus): m. Título de dignidad, honor ó señorío; como duque, conde, marqués, consejero, etc.

DIDÁCTICA (de didáctico): f. Arte de enseñar.

DIEZMAR (del lat. decimāre): a. Sacar de diez uno.

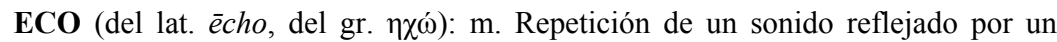
cuerpo duro. [...] -ECO: fig. El que, ó lo que, imita ó repite servilmente aquello que otro dice en otra parte.

\subsubsection{La definición}

Exceptuando los primeros pliegos a los que aquí se está haciendo referencia, el $D E H A$ tiene como repertorio fuente de la lengua común el $D R A E$ de 1884 (Pardo Herrero 2012: 178-179), de allí se toman, si no todas, casi todas sus entradas y acepciones y se reproducen las definiciones. Sin embargo, en las primeras páginas la definición de las voces que están en el $D R A E-1884$, pues también hay voces no marcadas que no estaban en el diccionario académico, no sale mayormente de allí. Hay ocasiones en que sí lo sigue, pero destaca que pese a notarse el uso del diccionario académico, se observen variaciones. En otras ocasiones la edición que se sigue, total o parcialmente, es la edición anterior, la de 1869, lo que se explicaría si consideramos que en 1883 Benot 
pudo comenzar a recoger información. Una tercera posibilidad es que siga a la Academia, pero no el DRAE-1884 ni 1869 sino Autoridades, lo que guardaría relación con la consideración de incluir en el diccionario la historia de la lengua, evidente en la decisión de incorporar ejemplos de uso.

Algunas muestras en las que se aprecia que en esos primeros pliegos el diccionario académico de 1884 es más una fuente que una plantilla seguida a pies juntillas, son las siguientes.

\begin{tabular}{|c|c|}
\hline DEHA & $D R A E-1884$ \\
\hline $\begin{array}{l}\text { ABANDONAR (del lat. abandonāre, o abandonnāre, } \\
\text { de abandonāre, fianza): v. a. Dejar en desamparo, } \\
\text { desamparar á una persona ó cosa. \| No hacer caso } \\
\text { ni aprecio de una persona ó cosa como inútil ó de } \\
\text { poca estima. } \\
\text { [citas de uso] } \\
\text { — ABANDONAR: entregar algo á los azares de lo } \\
\text { desconocido, ó a desdichas inesperadas. } \\
\text { [cita de uso] } \\
\text { — ABANDONAR: desechar. } \\
\text { [cita de uso] } \\
\text { — ABANDONAR: partir, ausentarse. } \\
\text { [cita de uso] } \\
\text { — ABANDONAR: desamparar un objeto estimable por } \\
\text { no poderlo mantener ni conservar, como abandonar } \\
\text { la plaza, el puesto, el campo. } \\
\text { [cita de uso] } \\
\text { - ABANDONAR: Zootec. [...] } \\
\text { — ABANDONAR: Equit. [...] } \\
\text { — ABANDONAR: Mil. [...] }\end{array}$ & $\begin{array}{l}\text { Abandonar. (Del b. lat. abandonāre.) a. } \\
\text { Dejar, desamparar á una persona ó cosa. } \\
\| \text { No hacer caso de ella. \| r. fig. Dejar- } \\
\text { se dominar por afectos, pasiones ó vi- } \\
\text { cios. } \| \text { fig. Descuidar uno sus intereses, } \\
\text { ó su aseo y compostura. } \| \text { fig. Caer de } \\
\text { ánimo, rendirse en las adversidades y } \\
\text { contratiempos. }\end{array}$ \\
\hline $\begin{array}{l}\text { ABANDONO (V. ABANDONAR): s. m. Acción y efecto } \\
\text { de abandonar ó abandonarse. \| Se usa en todas las } \\
\text { acepciones del verbo abandonar y abandonarse. } \| \\
\text { Desamparo. \| Descuido, negligencia. \| Dejadez, } \\
\text { desaliño, desaseo. } \| \text { Sencillez, naturalidad. }\end{array}$ & $\begin{array}{l}\text { Abandono. (Del b. lat. abandōnum.) m. } \\
\text { Acción y efecto de abandonar ó abando- } \\
\text { narse. }\end{array}$ \\
\hline $\begin{array}{l}\text { ABATIDAMENTE: adv, Con abatimiento, con poco } \\
\text { ánimo. \| Rendidamente, con vileza y desprecio. }\end{array}$ & Abatidamente. adv. m. Con abatimiento. \\
\hline 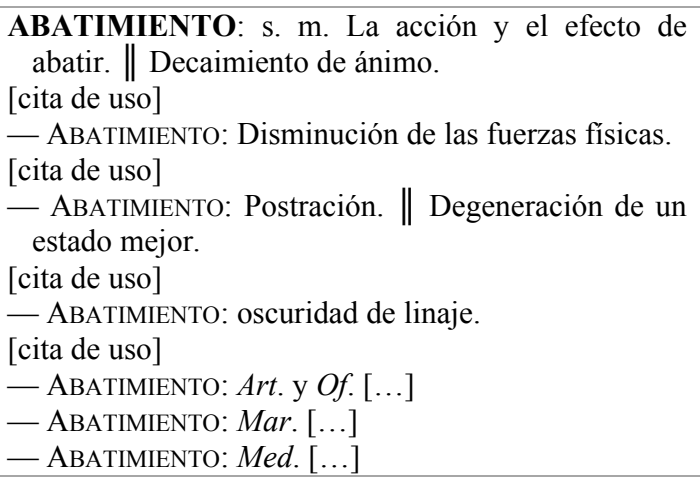 & $\begin{array}{l}\text { Abatimiento. m. Acción y efecto de abatir } \\
\text { ó abatirse. }\end{array}$ \\
\hline
\end{tabular}




\begin{tabular}{|l|l|}
\hline ABEJARRÓN: V. ABEJARUCO. & $\begin{array}{l}\text { Abejarrón. (aum. de abeja.) m. Insecto } \\
\text { con alas, de una pulgada de largo, ceni- } \\
\text { ciento, y que al volar zumba mucho. } \\
{[\ldots]}\end{array}$ \\
\hline
\end{tabular}

Destaca en estos casos que el DEHA suele ofrecer más acepciones, intentando desglosar más el significado de la palabra, así como la incorporación de acepciones específicas con marca de especialidad.

Por otra parte, la huella de Autoridades se evidencia en los siguientes ejemplos:

\begin{tabular}{|c|}
\hline DEHA \\
\hline ABAJAMIENTO s. f. La acción \\
y el efecto de abajar ó de quedar \\
abajada una cosa. «Es voz poco \\
usada», decía la Ac. Esp. en su \\
Dicc. de 1726. [autoridad] \\
- ABAJAMIENTO: s. m. La acción \\
y efecto de abajar. \| Rebaja ó \\
descuento. \| Bajeza, abatimien- \\
to, humillación, decaimiento.
\end{tabular}

ABAJAR: v. a. Bajar, descender: «en lo antiguo fué muy usado este verbo», decía la Ac. Esp. en su Dicc. de 1726.

- ABAJAR: v. a. Inclinar, mover hacia abajo una cosa, como abajar el cuerpo, bajar la cabeza. $[\ldots]$

Autoridades
ABAXAMIENTO. s. m. La
acción de abaxar, ó el efecto
de quedar abaxada alguna
cosa. Es voz poco usada. [...]

ABAXAR. v. n. Descender,
hacer movimiento desde la
parte superior à la inferiór y
baxa, y lo mismo que oy se
dice baxar. Componese de la
palábra Baxo y de la partícu-
la A, y en la antiguo fue mui
usado este verbo. [...]
ABAXAR. Muchas veces se
toma por inclinar, mover
hacia abaxo alguna cosa,
como abaxar el cuerpo, la
cabeza, \&c. [...]
ABANILLO. dim. tambien de

ABANILLO (dimin. de abano): s. $\mathrm{m}$. El abanico pequeño. (Ac. Esp. Dicc. de 1726)

Abáno. El abaníco pequeño. [...]

ABANILlo Vale tambien lo mismo que el fuelle, ó porción ahuecada, que havia en los cuellos alechugados, que antiguamente se usaron. [...]

ABANINO s. m. (Ac. Esp. Dicc. de 1726) Moda que en España introdujeron las damas de Palacio, que se reducía á una porción de gasa blanca de un palmo de largo, entorchada con unos como bollos, la cual se ponía atravesada ú ondeada en el escote del jubón, como los bolsillos ó maragatos; y con esta señal o divisa

ABANINO. s. m. Moda que en España introduxeron las Damas de Palacio, que se reducía à una porción de gasa blanca de un palmo de largo, entorchada con unos como bollos, la qual se ponía atravesada ù ondeada en el escóte del jubon como los bobillos, ò maragatos: y con esta
DRAE-1884

Abajamiento. m. ant. Acción y efecto de abajar.

\author{
Abajar. n. y. a. ant. Bajar.
}

Abanillo. (d. de abano.) $\mathrm{m}$. Adorno de lienzo afollado de que se formaban ciertos cuellos alechugados que se usaron en otro tiempo. \| Abanico, 1. a acep.
Abanino. (d. de abano.) $\mathrm{m}$. Porción de gasa ú otra tela blanca con que las mujeres guarnecían en ondas el escote del jubón. 


\begin{abstract}
(que sólo podían traer estas damas) se distinguían de las demás de la Villa y Corte, incluyendo misteriosamente en este adorno ó señal distintiva todos los atributos de veneración $\mathrm{y}$ rendimiento con que los caballeros que las servían las respetaban.
\end{abstract}

señal, ù divisa (que solo podían traher estas Damas) se distinguian de las demás de la Villa y Corte, incluyendo mysteriosamente en este adorno, ò señal distintiva todos los atributos de veneración y rendimiento, con que los Caballeros que las servían, las respetaban. [...]

ABASTAR (del baj. lat. bastāre, de bastus, suficiente): v. a. Es voz antigua y poco usada, decía la Ac. Esp. en 1726. \| Proveer o abastecer con abundancia. [...]

- Abastar: v. n. Bastar, ser suficiente. Era voz antigua en 1726 según el Dicc. primero de la Ac. Esp.
ABASTAR. V. a. Proveer, ò abastecer con abundancia. Es voz antigua y poco usada. [...]

ABASTAR v.n. Vale tambien lo mismo que bastar, ò ser suficiente. Es voz antigua. [...]
Abastar. (Del b. lat. bastāre, de bastus, suficiente): a. ant.

Abastecer. Usáb. t. c. r. $\|$ n. ant. Bastar o ser suficiente.

\subsubsection{La etimología}

Como en los puntos anteriores, en el caso de la etimología después de estos pliegos lo usual es utilizar la que ofrece el $D R A E$ (pueden verse como ejemplo las voces citadas en el punto 1: dictado, didáctica, diezmar, eco). Pero en estas páginas aunque a veces se sigue, hay propuestas nuevas o más información. En el caso de abandonar, que aparece citado en el punto 2, se puede observar. Otros ejemplos que se reproducen a continuación son ábaco y abad, donde se dan además equivalentes en otras lenguas; abarca, que indica la etimología de la Academia y añade otra; abajo, que intenta una etimología; y abdomen, donde la etimología coincide con la del DRAE pero va más allá y da propuestas. En estos dos ejemplos se reproduce también la definición para observar las diferencias con el $D R A E-1884^{6}$.

\begin{tabular}{|c|c|}
\hline DEHA & $D R A E-1884$ \\
\hline $\begin{array}{l}\text { ÁBACO (lat. abăcus, } i \text {; ó ábax, acis; de } \alpha \beta \alpha \xi \text {, que } \\
\text { en griego significa tablero, tabla, regularmente de } \\
\text { forma cuadrangular; de donde, en general, rec- } \\
\text { tángulo, cuadro, baldosa, casilla de un tablero, } \\
\text { como los de damas; y, por extensión, plato, dis- } \\
\text { co, el disco del sol: italiano abbaco; francés } a b a- \\
\text { que): } s . \text { m. En general, ÁBACO significa tablero ó } \\
\text { plancha rectangular de madera, tierra cocida, } \\
\text { mármol ó piedra de cualquier clase. [...] }\end{array}$ & $\begin{array}{l}\text { Ábaco. (Del lat. abăcus; del gr. } \alpha \beta \alpha \xi \text {.) m. Arq. } \\
\text { Parte superior en forma de tablero, que coro- } \\
\text { na el capital. \| Cuadro de madera con diez } \\
\text { cuerdas ó alambres paralelos y en cada uno de } \\
\text { ellos otras tantas bolas movibles, usado en las } \\
\text { escuelas para enseñar á los niños los rudi- } \\
\text { mentos de la aritmética. }\end{array}$ \\
\hline
\end{tabular}

${ }^{6}$ En este artículo se hace referencia a la lengua común pues es la que hace comparable el $D E H A$ con los diccionarios de Academia. Sin embargo cabe decir que en estos pliegos, a diferencia de los posteriores, pueden verse paréntesis etimológicos también en nombres propios (s. v. Abante). 
ABAD Etim. (V. ABA y ABBA: abbās abbātis, abad; sir. $a b a$ abba, hebreo $a b$ padre; provenz. abbat; port. abbade; it. abbate; franc. antiguo $a b e$; franc. moderno abbé; inglés abbot. Ab, aub y abbot son prefijos en anglo-sajón que significan abadía, como en Abton, Abington, Abbotsburg; abbe lo es en francés Abbeville. \| Abad, en persa tiene otra acepción: significa ciudad, residencia; Fyabad, hermosa ciudad; Abbas, $a b a d$, habitación paterna).

- ABAD: El superior o primero entre los monjes.

- ABAD: El superior y cabeza de algunas iglesias colegiales $[\ldots]$

- ABAD: En algunas catedrales de España había dignidades con el título de ABAD. [...]

- ABAD: Antiguamente, sin distinción ni diferencia, se llamaba así al cura ó párroco de alguna iglesia; pero, andando el tiempo, solamente ha quedado el uso de esta voz con ese significado en Galicia, Asturias, Portugal, Navarra y Cataluña. [...]

ABAJO (de $a$ y bajo: probablemente la raíz de bajo sea céltica: en irl. hay bas; en gaél. bas y bazu. Compárese con el griego ßá $\sigma \sigma \omega v$, dór. $\mathrm{B} \alpha 0 \mathrm{ù} \zeta$, profundo, vasto, abundante, gordo, de donde el lat. bassus, gordo): adv. Contrapuesto á arriba. [...]

ABARCA (la Academia deriva esta voz del bajo latín abārca; otros la derivan del vascongado abarquīá ó abárquīa, que significa los mismo que en español): s. f. Calzado rústico, que se hace de pellejo de jabalí, cuero de buey, caballo, etc., sin adobar: cubre la planta, los dedos y algunas veces mayor parte del pié, y se ata con unas cuerdas ó correas sobre el empeine y el tobillo. A veces se cubre de bayeta el pié y la pierna para que las correas no lastimen. Este calzado es muy cómodo en tiempo seco, pero no cuando llueve ó nieva, por lo mucho que el cuero se reblandece.

ABDOMEN (del lat. abdōmen; ¿de abdère, ocultar, y omentum, redaño? ¿o una contracción y transposición de adipōmen, de adeps, enjundia? ¿del gr. v́ s. m. Gran cavidad esplánica que forma la mitad inferior del tronco, y aloja la mayor parte de los órganos digestivos y génito-urinarios.

La diferencia entre las etimologías que se aprecia en esta muestra, revela a Benot como un comparativista, seguidor de esta corriente historicista inaugurada en Alemania
Abad. (Del lat. abbās, abbāatis.) m. Superior de un monasterio. II Superior de una colegiata. II En algunas catedrales, título de dignidad. $\|$ En Galicia, Navarra y otras provincias, Cura, 1. acep. [...]

Abajo. adv. 1. Á ó en lugar ó parte inferior. En lugar posterior, ó que está después de otro. $[\ldots]$

Abarca. (Del b. lat. abārca.) f. Calzado rústico, que se hace de cuero de buey, caballo, etc., sin adobar: cubre la planta, los dedos y algunas veces mayor parte del pie, y se ata con unas cuerdas ó correas sobre el empeine y el tobillo.

Abdomen. (Del lat. abdōmen.) m. Cavidad del tronco humano que limitan por arriba el diafragma; por debajo, la pelvis; por delante y por los lados, las paredes musculares; por detrás las vértebras lumbares. Divídese por su parte anterior en tres regiones [...] 
y seguida en castellano por, entre otros, el importante filólogo colombiano Rufino José Cuervo, cuya obra conocía el español y que es probable que le influenciara. ${ }^{7}$

A las tres cuestiones de microestructura a que se ha hecho referencia para evidenciar una composición particular del diccionario que es factible atribuir a Eduardo Benot, puede sumarse también el tratamiento dado a los americanismos.

Los americanismos que han podido localizarse en el cuerpo del DEHA, considerando como tales solo los que tienen marca diatópica, son 236 (Pardo Herrero 2012). De ellos 131 siguen al $D R A E-1884,75$ entrarán posteriormente en la lexicografía académica y 30 no lo harán nunca. Pero si se observa el inicio del $D E H A$, se comprueba que 107 de esas 236 voces están, precisamente, al comienzo, en la letra $a$, o sea un $45 \%$. De esas 107, solamente 26 provienen del DRAE-1884, las otras 81 provienen de otras fuentes, lo que permite constatar dos cuestiones: primero, que en el inicio del $D E H A$ el diccionario académico no era la principal fuente de voces americanas; y segundo, que incluir esas voces era parte del objetivo global del DEHA.

Estos números indican un interés evidente por los americanismos que quizá sea producto de la influencia de $\operatorname{Benot}^{8}$, pues al avanzar en el alfabeto, la inserción de voces americanas se reduce, reapareciendo mucho más tarde, en el segundo apéndice, dirigido por Pelayo Vizuete.

\section{CONCLUSIÓN}

El inicio del DEHA, en particular los primeros catorce pliegos, es distinto de lo que va a seguir. Las diferencias se explican por las circunstancias cambiantes durante la generación del proyecto, como fue la sustitución del director, y la definición de la forma en que se llevaría a cabo la obra. Estos problemas iniciales no impiden que se inicie la publicación y explican en gran medida la falta de un prólogo a la obra pues las ideas no estaban del todo claras ni tampoco el liderazgo. También se entiende que, a diferencia de otras obras contemporáneas, en la portada del DEHA no se diga que se sigue al DRAE, pues dado que al comienzo no se hace, no se puede decir. Por último, esa inestabilidad inicial que derivó en que Pagès no comenzara de cero si no que hiciera uso de

${ }^{7}$ La utilización del primer volumen del Diccionario de construcción y régimen (1886) de Cuervo en la elaboración del DEHA se comprueba en algunas citas de uso tomadas de allí (Prieto García-Seco 2007: 108-109, Pardo Herrero 2012: 203-205); otra de sus obras, las Apuntaciones críticas sobre el lenguaje bogotano (1867-1872), también fue utilizada como fuente de voces americanas, colombianas particularmente, en el inicio del DEHA, que como se viene comprobando, es donde habría participado Benot (Pardo Herrero 2012: 240). Una influencia más podría considerarse la etimología de la voz abandono, que mientras el DRAE la considera proveniente del latín, el DEHA la entiende como un sustantivo derivado del verbo abandonar, que es como lo entiende también Cuervo en su Diccionario, aunque esto puede deberse simplemente a una visión similar acerca de la etimología. Así mismo, la mayor cantidad de acepciones que se evidenció en el punto 2 sobre la definición, recuerda el trabajo realizado por Cuervo, quien también buscaba en su diccionario desglosar lo más posible en forma de subacepciones el significado de las voces de su nomenclatura, en relación directa con su uso en textos escritos, para observar así su historia de forma precisa y completa.

${ }^{8}$ Un ejemplo en el contexto de los americanismos que evidencia que no sigue al $D R A E-1884$ es que no aparece el americanismo abajero, entre abajar y abajo. Esta palabra solo se incluirá en el DEHA en el apéndice segundo. 
lo avanzado por Benot, «justifica» las duplicaciones de categorías gramaticales observadas en la obra, así como en la lista de abreviaturas que hay al principio del tomo 1 (Pardo Herrero 2012: 138-139).

En cuanto al trabajo de Eduardo Benot, aunque esos catorce primeros pliegos no se puede afirmar que fueron redactados por él, sí es posible considerar que en ellos está la huella de su labor. Basándonos en esas páginas y en lo que sabemos de las circunstancias por las cartas de Pagès y Pi y Margall, se interpreta que el diccionario que Benot se proponía realizar era inmenso, pues pretendía no solo contener todas las voces sino también recoger todo el conocimiento, como apuntaba Pagès, si bien lo consideraba un defecto que comprometía su visibilidad comercial. Además, las entradas de lengua común, que en su gran mayoría provienen del DRAE 1884, en los pliegos referidos no provienen de allí, aunque haya excepciones, lo que indica que la idea sería hacer un diccionario de nueva planta, o al menos que no tuviera como única referencia el diccionario académico. En cuanto a los textos enciclopédicos, los comentarios de Pagès sobre la entrada abeja y Aarón hacen pensar que Benot querría redactar menos, o al menos revisarlo, lo que resulta muy interesante $\mathrm{y}$, en la práctica, hubiera requerido un enorme esfuerzo.

El $D E H A$, pese a las dificultades, empezó a publicarse y llegó a su fin, pero el diccionario enciclopédico de Benot quedó inacabado. Observar esos primeros pasos de la obra en cuestión y las páginas iniciales evidencia cuán importante es dedicar parte de la investigación a la cuestión histórica y metalexicográfica, que unidas al hecho de «dejar hablar» al repertorio permiten entenderlo cabalmente al tener de él tanto una visión total, como producto cerrado y terminado, como una visión del proceso que sigue para llegar a ser tal.

\section{REFERENCIAS BIBLIOGRÁFICAS}

AHUMADA, Ignacio (2007) «Las lenguas de cultura no deben mirar desde la distancia el desarrollo de sus lenguas de especialidad...», en Donde dice... Boletín de la Fundación del Español Urgente 9 (oct.-dic.), pp. 2-3.

Azorín, Dolores (1996): «La lexicografía española en el siglo XIX: del diccionario a la enciclopedia», Estudios de lingüística, 11, pp. 111-122.

Chabrán, Rafael (2000): «El Diccionario Enciclopédico Hispano-Americano y el pensamiento español». Ponencia inédita presentada en el XII Seminario de Historia de la Filosofía Española e Iberoamericana, celebrado en la Universidad de Salamanca.

GutiÉRrez CUADRADO, Juan (1994): «El Diccionario Hispano-americano de Montaner y Simón», en Joaquín Marco Revilla, coord., Actas del XXIX Congreso del Instituto Internacional de Literatura Iberoamericana, Barcelona, PPU, pp. 263-282.

- (2012): «Los diccionarios inacabados», en Antoni Nomdedeu et. al, eds., Avances de lexicografía hispánica, Tarragona, Universitat Rovira i Virgili, 1, pp. 29-60.

JiMÉNEZ GARCíA, Antonio (1996): El krausopositivismo de Urbano González Serrano, Badajoz, Diputación Provincial de Badajoz.

Palau Y Dulcet, Antonio (1949²): Manual del librero hispano-americano, Barcelona, Librería Anticuaria de A. Palau, II, pp. 168-169. 
PARdo Herrero, Pilar (2012): El Diccionario Enciclopédico Hispano-Americano de Montaner y Simón: a propósito del léxico de la ciencia y de la técnica, Tesis doctoral inédita consultable en http://hdl.handle.net/10803/96707.

— y Cecilio GARRIGA (2012): «El Diccionario Enciclopédico Hispano-Americano: notas sobre la autoría y el tratamiento del español de América», en Antoni Nomdedeu et al., eds., Avances de lexicografia hispánica, Tarragona, Universitat Rovira i Virgili, 1, pp. 455-469.

PRIETO GARCÍA-SECO, David (2007): «El Diccionario enciclopédico hispano-americano de literatura, ciencias y artes (1887-1910) de la editorial Montaner y Simón», Boletín de la Real Academia Española, 87, 295, pp. 97-121.

- (2008): «El Diccionario enciclopédico hispano-americano de literatura, ciencias y artes (1887-1910) de la editorial Montaner y Simón: primera aproximación», en Esteban Tomás Montoro del Arco et al., coords., Nuevas perspectivas en torno a la diacronía lingüistica, Granada, AJIHLE-Universidad de Granada, pp. 421-439.

- (2009): «El Diccionario enciclopédico hispano-americano de literatura, ciencias y artes (1887-1910) de la editorial Montaner y Simón: reflexiones en torno a su nomenclatura y sus fuentes textuales», en José María García Martín, dir., Ideas y realidades lingüísticas en los siglos XVIII y XIX, Cádiz, Universidad de Cádiz, pp. 535-550.

- (2010): "Las autoridades del Diccionario enciclopédico hispanoamericano de literatura, ciencia y artes (1887-1898) de la editorial Montaner y Simón», RILCE. Revista de Filología Hispánica, 26, 2, pp. 383-401.

REAL ACADEMIA ESPAÑOLA (1726-1739): Diccionario de la lengua castellana, en que se explica el verdadero sentido de las voces, su naturaleza y calidad, con las phrases o modos de hablar, los proverbios o refranes, y otras cosas convenientes al uso de la lengua, Madrid, Imprenta de Francisco del Hierro.

$-\left(1869^{11}\right)$ : Diccionario de la lengua castellana, Madrid, Imprenta de Don Manuel Rivadeneyra.

- $\left(1884^{12}\right)$ : Diccionario de la lengua castellana, Madrid, Imprenta de D. Gregorio Hernando.

VV. AA. (1887-1910): Diccionario Enciclopédico Hispano-Americano. Barcelona, Montaner y Simón.

\section{APÉNDICES}

\section{I}

TRANSCRIPCIÓN DEL CONTRATO ENTRE ANICETO DE PAGÈS Y MONTANER Y SIMÓN EDITORES

Los señores Montaner y Simon y Don Aniceto de Pagès han tratado de común acuerdo lo siguiente:

$1^{\circ}$ Los señores Montaner y Simon encargan al Sr. Pagès la organización y confección del Diccionario Enciclopédico hispano-americano, con la obligación de que el original debe 
estar escrito por los señores que figuran en la portada del libro, obligándose aquellos á pagarle treinta y tres duros por cada ochenta mil letras.

$2^{\circ} \mathrm{El} \mathrm{Sr}$. Pagès tendrá derecho á tomar de la casa cuatro mil pesetas mensualmente sin interrupción de ninguna clase ni por ningún concepto, obligándose este á su vez a entregar por lo menos treinta pliegos mensuales de ochenta mil letras cada pliego.

$3^{\circ}$ La extención [sic] de la obra será de veinte tomos de mis páginas cada uno, y para que conste lo firman en Barcelona á 26 de Marzo de 1887.

Aniceto de Pagés

Montaner y Simon

\author{
II \\ TRANSCRIPCIÓN DE LAS CUENTAS DE ABONO \\ DE LOS DOS TOMOS DEL PRIMER APÉNDICE DEL DEHA
}

CuENTA DE ABONO TOMO 24

Cuenta de abono á Don Aniceto de Pages de Madrid por el original de texto del tomo 24 $1^{\mathrm{o}}$ del Apéndice del Diccionario Enciclopedico.

Total de letras impresas en el tomo 24 - 12.480 .000

De ello resultan 156 pliegos de original á razon de 80.000 letras el pliego, que pagadas á 165 pesetas el pliego según tenemos convenido importan pesetas $25,740 \#$ veinticinco mil setecientos cuarenta\# que es la cantidad que pasamos al credito de su cuenta.

Barcelona 27 de junio 1899.

Es conforme

Montaner y Simon
Es conforme

Aniceto de Pagés

\title{
CUENTA DE ABONO TOMO 25
}

Cuenta de abono á Don Aniceto de Pages de Madrid por el original de texto del tomo 25 del Diccionario Enciclopedico. $2^{\circ}$ del Apendice. 
Importe de 162 1/2 pliegos de original que resultan en el tomo 25 , que pagados á 165 pesetas según tenemos convenido importa pesetas $26,812^{, 50}$ veintiseis mil ochocientas doce con 50 centimos _ que es la cantidad que pasamos al credito de su cuenta.

Barcelona 26 de Mayo 1900.

Es conforme

Montaner y Simon
Es conforme

Aniceto de Pagés 